\title{
Genome sequence of the soil bacterium Saccharomonospora azurea type strain (NA-128 ${ }^{\mathrm{T}}$ )
}

\author{
Hans-Peter Klenk ${ }^{1 *}$, Brittany Held ${ }^{2}$, Susan Lucas ${ }^{3}$, Alla Lapidus ${ }^{3}$, Alex Copeland ${ }^{3}$, Nancy \\ Hammon $^{3}$, Sam Pitluck ${ }^{3}$, Lynne A. Goodwin ${ }^{2,3}$, Cliff Han ${ }^{2,3}$, Roxanne Tapia ${ }^{2,3}$, Evelyne-Marie \\ Brambilla $^{1}$, Gabriele Pötter ${ }^{1}$, Miriam Land ${ }^{3,4}$, Natalia Ivanova ${ }^{3}$, Manfred Rohde ${ }^{5}$, Markus \\ Göker ${ }^{1}$, John C. Detter ${ }^{2,3}$, Nikos C. Kyrpides ${ }^{3}$, and Tanja Woyke \\ ${ }^{1}$ Leibniz Institute DSMZ - German Collection of Microorganisms and Cell Cultures, \\ Braunschweig, Germany \\ ${ }^{2}$ Los Alamos National Laboratory, Bioscience Division, Los Alamos, New Mexico, USA \\ ${ }^{3}$ DOE Joint Genome Institute, Walnut Creek, California, USA \\ ${ }^{4}$ Oak Ridge National Laboratory, Oak Ridge, Tennessee, USA \\ ${ }^{5} \mathrm{HZI}$ - Helmholtz Centre for Infection Research, Braunschweig, Germany \\ *Corresponding author: Hans-Peter Klenk
}

Keywords: aerobic, chemoheterotrophic, Gram-positive, vegetative and aerial mycelia, spore-forming, non-motile, soil bacterium, Pseudonocardiaceae, CSP 2010

Saccharomonospora azurea Runmao et al. 1987 is a member of the genus Saccharomonospora, which is in the family Pseudonocardiaceae and thus far poorly characterized genomically. Members of the genus Saccharomonospora are of interest because they originate from diverse habitats, such as leaf litter, manure, compost, the surface of peat, and moist and over-heated grain, and may play a role in the primary degradation of plant material by attacking hemicellulose. Next to $S$. viridis, S. azurea is only the second member in the genus Saccharomonospora for which a completely sequenced type strain genome will be published. Here we describe the features of this organism, together with the complete genome sequence with project status 'Improved high quality draft', and the annotation. The 4,763,832 bp long chromosome with its 4,472 protein-coding and 58 RNA genes was sequenced as part of the DOE funded Community Sequencing Program (CSP) 2010 at the Joint Genome Institute (JGI).

\section{Introduction}

Strain NA-128 $(=$ DSM $44631=$ ATCC $43670=$ NBRC 14651) is the type strain of the species Saccharomonospora azurea [1], one of nine species currently in the genus Saccharomonospora [2]. The strain was originally isolated in the course of screening for new antibiotics from a soil sample collected near Guangyun City, Sichuan (China) [1]. The genus name Saccharomonospora was derived from the Greek words for sakchâr, sugar, monos, single or solitary, and spora, a seed or spore, meaning the sugar (-containing) single-spored (organism) [3]. The species epithet was derived from the Latin adjective azurea, azure, referring to the color of the areal mycelium [1]. Yoon et al. [4] showed in 1999 via DNA-DNA hybridization that 'S. caesia' [5] (formerly known as 'Micropolyspora caesia' [6]), which was not included on the
Approved Lists [7], was a synonym of $S$. azurea. $S$. azurea and the other type strains of the genus Saccharomonospora were selected for genome sequencing in a DOE Community Sequencing Project (CSP 312) at Joint Genome Institute (JGI), because members of the genus (which originate from diverse habitats, such as leaf litter, manure, compost, surface of peat, moist and over-heated grain) might play a role in the primary degradation of plant material by attacking hemicellulose. This expectation was underpinned by the results of the analysis of the genome of $S$. viridis [8], one of the recently sequenced GEBA genomes [9]. The $S$. viridis genome, the only sequenced genome from the genus Saccharomonospora to date, contained an unusually large number (24) of genes for glycosyl hydrolases $(\mathrm{GH})$ belonging to $14 \mathrm{GH}$ fami- 
lies, which were identified in the Carbon Active Enzyme Database [10]. Hydrolysis of cellulose and starch was also reported for other members of the genus (that are included in CSP 312), such as $S$. marina [11], S. halophila [12], S. saliphila [13], S. paurometabolica [14], and S. xinjiangensis [15]. Here we present a summary classification and a set of features for $S$. azurea $\mathrm{AN}-128^{\mathrm{T}}$, together with the description of the genomic sequencing and annotation.

\section{Classification and features}

A representative genomic $16 \mathrm{~S}$ rRNA sequence of $S$. azurea NA-128 ${ }^{\mathrm{T}}$ was compared using NCBI BLAST $[16,17]$ under default settings (e.g., considering only the high-scoring segment pairs (HSPs) from the best 250 hits) with the most recent release of the Greengenes database [18] and the relative frequencies of taxa and keywords (reduced to their stem [19]) were determined, weighted by BLAST scores. The most frequently occurring genera were Saccharomonospora (47.9\%), Kocuria (17.7\%), Corynebacterium (9.4\%), Kibdelosporangium (6.0\%) and Prauserella (5.5\%) (176 hits in total). Regarding the eight hits to sequences from members of the species, the average identity within HSPs was $99.5 \%$, whereas the average coverage by HSPs was $99.8 \%$. Regarding the 42 hits to sequences from other members of the genus, the average identity within HSPs was $97.0 \%$, whereas the average coverage by HSPs was $98.3 \%$. Among all other species, the one yielding the highest score was Saccharomonospora xinjiangensis (AJ306300), which corresponded to an identity of $98.9 \%$ and an HSP coverage of $100.1 \%$. (Note that the Greengenes database uses the INSDC (= EMBL/NCBI/DDBJ) annotation, which is not an authoritative source for nomenclature or classification.) The highest-scoring environmental sequence was FN667533 'stages composting process pilot scale municipal drum compost clone PS3734', which showed an identity of $100.0 \%$ and a HSP coverage of $97.9 \%$. The most frequently occurring keywords within the labels of all environmental samples that produced hits were 'feedlot' (7.9\%), 'top' (4.1\%), 'beef, cattl, coli, escherichia, habitat, marc, neg, pen, primari, secondari, stec, surfac, synecolog' (3.9\%), 'feedbunk' (2.3\%) and 'compost' (1.7\%) (74 hits in total). Environmental samples that yielded hits of a higher score than the highest scoring species were not found.

Figure 1 shows the phylogenetic neighborhood of $S$. azurea in a $16 \mathrm{~S}$ rRNA based tree. The sequences of the three identical 16S rRNA gene copies in the genome do not differ from the previously published 16S rRNA sequence (Z38017).

Cells of $S$. azurea NA-128 ${ }^{\mathrm{T}}$ form an irregularly branched vegetative mycelium of 0.3 to $0.4 \mu \mathrm{m}$ diameter (Figure 2) [1]. The monopodally branching aerial mycelium has a diameter of 0.3 to 0.6 $\mu \mathrm{m}$ [1]; the mature mycelium and the spores are azure to cyaneus when grown on Oatmeal agar (ISP3) or on Czapek sucrose agar [1]. Smooth, round spores are 0.8 to $1.0 \mathrm{mM}$ long, mostly found on the aerial mycelium, but rarely on the substrate mycelium [1]. No distinct soluble pigment was detectable [1]. The growth range of strain NA-128 spans from $24-40^{\circ} \mathrm{C}$, with an optimum at $28-37^{\circ} \mathrm{C}$ [1]. Strain NA-128 ${ }^{\mathrm{T}}$ grows well in up to $7 \% \mathrm{NaCl}$ containing medium, but is inhibited at $10 \% \mathrm{NaCl}$ [1]. Physiological characteristics such as growth substrates, gelatin formation and peptonization of milk are described in detail by Runmao (1987) [1].

\section{Chemotaxonomy}

The cell wall of strain AN-128 ${ }^{\mathrm{T}}$ contains mesodiaminopimelic acid. Galactose and arabinose are present, indicating a type IV cell wall / type A whole cell sugar pattern [1]. The fatty acids spectrum is dominated by almost $80 \%$ hexadecanoic acids: iso- $\mathrm{C}_{16: 0}(27.0 \%), \mathrm{C}_{16: 1 \text { cis-9 }}(17.0 \%)$, iso- $\mathrm{C}_{16: 02}$ он (14.0\%), $\mathrm{C}_{16: 0}$ (palmitic acid, 13.0\%), iso- $\mathrm{C}_{16: 1 \mathrm{H}}$ (7.0\%), anteiso- $\mathrm{C}_{16: 0}(1.0 \%)$ [42]. There are no data available for polar lipids and quinines of this strain.

\section{Genome sequencing and annotation Genome project history}

This organism was selected for sequencing as part of the DOE Joint Genome Institute Community Sequencing Program (CSP) 2010, CSP 312, "Whole genome type strain sequences of the genus Saccharomonospora - a taxonomically troubled genus with bioenergetic potential". The genome project is deposited in the Genomes On Line Database [26] and the complete genome sequence is deposited in GenBank. Sequencing, finishing and annotation were performed by the DOE Joint Genome Institute (JGI). A summary of the project information is shown in Table 2. 


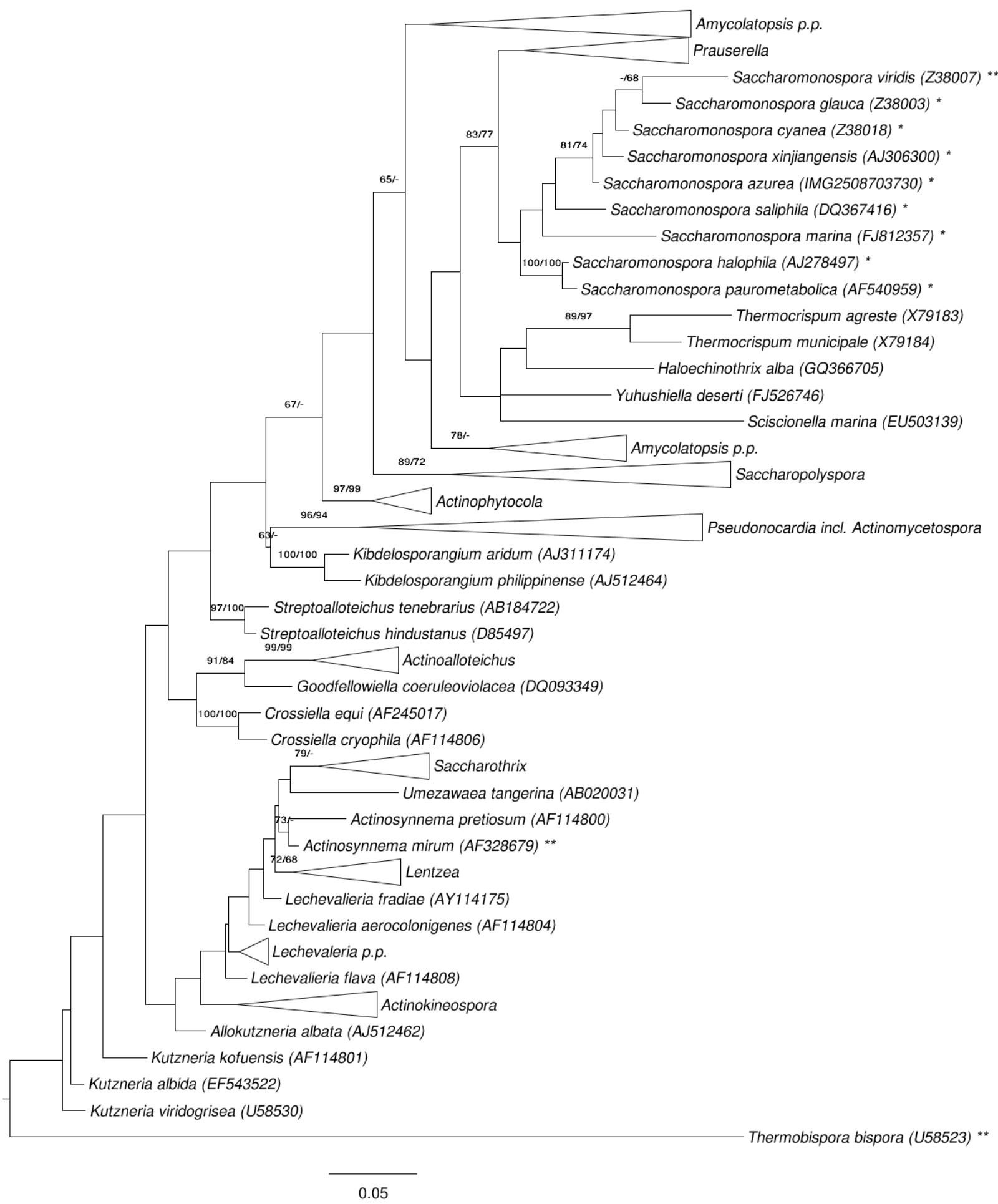

Figure 1. Phylogenetic tree highlighting the position of $S$. azurea relative to the type strains of the other species within the family Pseudonocardiaceae. The tree was inferred from 1,386 aligned characters [20,21] of the 16S rRNA gene sequence under the maximum likelihood (ML) criterion [22]. Rooting was done initially using the midpoint method [23] and then checked for its agreement with the current classification (Table 1). The branches are scaled in terms of the expected number of substitutions per site. Numbers adjacent to the branches are support values from $550 \mathrm{ML}$ bootstrap replicates [24] (left) and from 1,000 maximum parsimony bootstrap replicates [25] (right) if larger than 60\%. Lineages with type strain genome sequencing projects registered in GOLD [26] are labeled with one asterisk, those also listed as 'Complete and Published' with two asterisks $[8,27,28]$. Actinopolyspora iraqiensis Ruan et al. 1994 was ignored in the tree. The species was proposed to be a later heterotypic synonym of S. halophila [29], although the name A. iraqiensis would have had priority over $S$. halophila. This taxonomic problem will soon be resolved with regard to the genomes of $A$. iraqiensis and S. halophila, which were both part of CSP 312. 


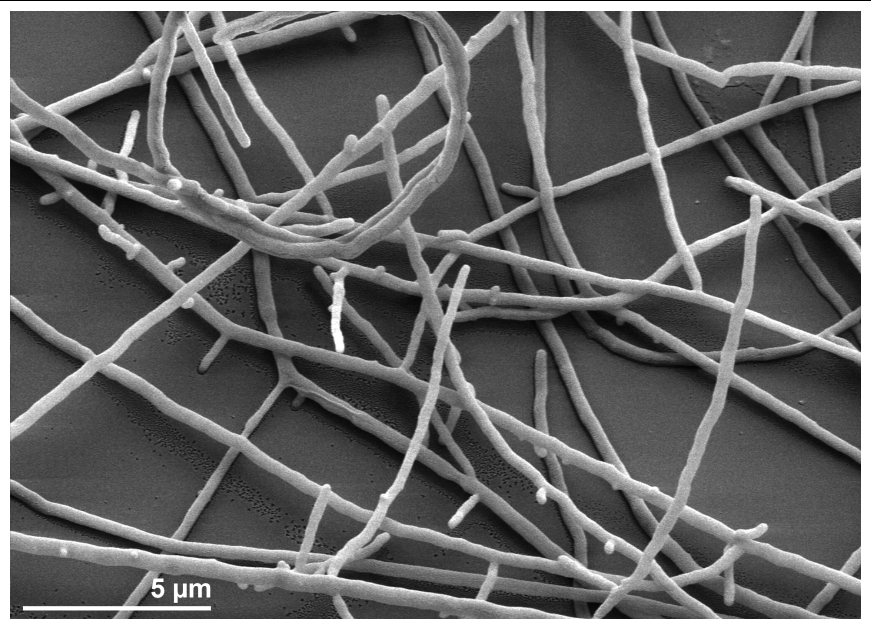

Figure 2. Scanning electron micrograph of $S$. azurea $\mathrm{AN}-128^{\mathrm{T}}$

Table 1. Classification and general features of S. azurea AN-128 ${ }^{\top}$ according to the MIGS recommendations [30].

\begin{tabular}{|c|c|c|c|}
\hline MIGS ID & Property & Term & Evidence code \\
\hline & \multirow{10}{*}{ Current classification } & Domain Bacteria & TAS [31] \\
\hline & & Phylum Actinobacteria & TAS [32] \\
\hline & & Class Actinobacteria & TAS [33] \\
\hline & & Subclass Actinobacteridae & TAS $[33,34]$ \\
\hline & & Order Actinomycetales & TAS $[7,33-35]$ \\
\hline & & Suborder Pseudonocardineae & TAS $[33,34,36]$ \\
\hline & & Family Pseudonocardiaceae & TAS $[33,34,36-38]$ \\
\hline & & Genus Saccharomonospora & TAS $[7,39]$ \\
\hline & & Species Saccharomonospora azurea & TAS [1] \\
\hline & & Type-strain AN-128 & TAS [1] \\
\hline & Gram stain & positive & NAS \\
\hline & Cell shape & variable & NAS \\
\hline & Motility & non-motile & NAS \\
\hline & Sporulation & $\begin{array}{l}\text { single spores with smooth surface, mainly on } \\
\text { aerial mycelium }\end{array}$ & TAS [1] \\
\hline & Temperature range & mesophile, $24-40^{\circ} \mathrm{C}$ & TAS [1] \\
\hline & Optimum temperature & $28-37^{\circ} \mathrm{C}$ & TAS [1] \\
\hline & Salinity & grows in up to $7 \% \mathrm{NaCl} ; 10 \%$ is inhibitory & TAS [1] \\
\hline \multirow[t]{3}{*}{ MIGS-22 } & Oxygen requirement & aerobic & TAS [1] \\
\hline & Carbon source & Mono, di- and trisaccharides & TAS [1] \\
\hline & Energy metabolism & chemoheterotrophic & NAS \\
\hline MIGS-6 & Habitat & soil & TAS [1] \\
\hline MIGS-15 & Biotic relationship & free living & NAS \\
\hline \multirow[t]{2}{*}{ MIGS-14 } & Pathogenicity & none & NAS \\
\hline & Biosafety level & 1 & TAS [40] \\
\hline MIGS-23.1 & Isolation & soil & TAS [1] \\
\hline MIGS-4 & Geographic location & Guangyuan City, Sichuan (China) & TAS [1] \\
\hline MIGS-5 & Sample collection time & 1986 or before & NAS \\
\hline MIGS-4.1 & Latitude & 32.45 & NAS \\
\hline MIGS-4.2 & Longitude & 105.84 & NAS \\
\hline MIGS-4.3 & Depth & not reported & \\
\hline MIGS-4.4 & Altitude & not reported & \\
\hline
\end{tabular}

Evidence codes - IDA: Inferred from Direct Assay (first time in publication); TAS: Traceable Author Statement (i.e., a direct report exists in the literature); NAS: Non-traceable Author Statement (i.e., not directly observed for the living, isolated sample, but based on a generally accepted property for the species, or anecdotal evidence). These evidence codes are from the Gene Ontology project [41]. If the evidence code is IDA, then the property was directly observed for a living isolate by one of the authors or an expert mentioned in the acknowledgements. 


\begin{tabular}{lll}
\multicolumn{2}{l}{ Table 2. Genome sequencing project information } \\
\hline MIGS ID & Property & Term \\
\hline MIGS-31 & Finishing quality & Improved high quality draft \\
& & Three genomic libraries: one 454 pyrosequence standard library, one \\
MIGS-28 & Libraries used & Illumina GAii, 454 GS FLX Titanium \\
MIGS-29 & Sequencing platforms & $1,025.0 \times$ Illumina; 8.6 × pyrosequence \\
MIGS-31.2 & Sequencing coverage & Newbler version 2.3, Velvet version 1.0.13, phrap version SPS - 4.24 \\
MIGS-30 & Assemblers & Prodigal \\
MIGS-32 & Gene calling method & AGIU00000000, CM001466 insert size), one Illumina library \\
& INSDC ID & March 6, 2012 \\
& GenBank Date of Release & Gi07579 \\
& GOLD ID & 62037 \\
& NCBI project ID & 2508501044 \\
& Database: IMG & DSM 44631 \\
& Source material identifier & Bioenergy and phylogenetic diversity \\
\hline
\end{tabular}

\section{Growth conditions and DNA isolation}

Strain NA-128' ${ }^{\text {T }}$ DSM 44631, was grown in DSMZ medium 83 (Czapek Peptone Medium) [43] at $28^{\circ} \mathrm{C}$. DNA was isolated from $0.5-1 \mathrm{~g}$ of cell paste using Jetflex Genomic DNA Purification Kit (GENOMED 600100) following the standard protocol as recommended by the manufacturer with the following modifications: extended cell lysis time $(60$ min.) with additional $30 \mu \mathrm{l}$ Achromopeptidase, Lysostaphin, Mutanolysin; proteinase $\mathrm{K}$ was applied in 6-fold the supplier recommended amount for $60 \mathrm{~min}$. at $58^{\circ} \mathrm{C}$. The purity, quality and size of the bulk gDNA preparation were assessed by JGI according to DOE-JGI guidelines. DNA is available through the DNA Bank Network [44].

\section{Genome sequencing and assembly}

The genome was sequenced using a combination of Illumina and 454 sequencing platforms. All general aspects of library construction and sequencing can be found at the JGI website [45]. Pyrosequencing reads were assembled using the Newbler assembler (Roche). The initial Newbler assembly consisting of 215 contigs in one scaffold was converted into a phrap [46] assembly by making fake reads from the consensus, to collect the read pairs in the 454 paired end library. Illumina GAii sequencing data $(5,162.6 \mathrm{Mb})$ was assembled with Velvet [47] and the consensus sequences were shredded into $1.5 \mathrm{~kb}$ overlapped fake reads and assembled together with the 454 data. The 454 draft assembly was based on $80.3 \mathrm{Mb} 454$ draft data and all of the 454 paired end data. Newbler parameters are $\begin{array}{llllllllll}\text { consed } & -\mathrm{a} & 50 & -\mathrm{l} & 350 & -\mathrm{g} & -\mathrm{m} & -\mathrm{ml} & 20 . & \text { The }\end{array}$ Phred/Phrap/Consed software package [46] was used for sequence assembly and quality assessment in the subsequent finishing process. After the shotgun stage, reads were assembled with parallel phrap (High Performance Software, LLC). Possible mis-assemblies were corrected with gapResolution [45], Dupfinisher [48], or sequencing cloned bridging PCR fragments with subcloning. Gaps between contigs were closed by editing in Consed, by PCR and by Bubble PCR primer walks (J.-F. Chang, unpublished). A total of 158 additional reactions were necessary to close gaps and to raise the quality of the finished sequence. Illumina reads were also used to correct potential base errors and increase consensus quality using a software Polisher developed at JGI [49]. 
Klenk et al.

The error rate of the completed genome sequence is less than 1 in 100,000 . Together, the combination of the Illumina and 454 sequencing platforms provided 1,033.6 $\times$ coverage of the genome. The final assembly contained 345,324 pyrosequence and 64,928,268 Illumina reads.

\section{Genome annotation}

Genes were identified using Prodigal [50] as part of the Oak Ridge National Laboratory genome annotation pipeline, followed by a round of manual curation using the JGI GenePRIMP pipeline [51]. The predicted CDSs were translated and used to search the National Center for Biotechnology Information (NCBI) non-redundant database, UniProt, TIGRFam, Pfam, PRIAM, KEGG, COG, and
InterPro databases. Additional gene prediction analysis and functional annotation was performed within the Integrated Microbial Genomes - Expert Review (IMG-ER) platform [52].

\section{Genome properties}

The genome consists of a 4,763,852 bp long chromosome with a $70.1 \% \mathrm{G}+\mathrm{C}$ content (Table 3 and Figure 3). Of the 4,530 genes predicted, 4,472 were protein-coding genes, and 58 RNAs; 96 pseudogenes were also identified. The majority of the protein-coding genes $(73.8 \%)$ were assigned a putative function while the remaining ones were annotated as hypothetical proteins. The distribution of genes into COGs functional categories is presented in Table 4.

Table 3. Genome Statistics

\begin{tabular}{lrr}
\hline Attribute & Value & \% of Total \\
\hline Genome size (bp) & $4,763,852$ & $100.00 \%$ \\
DNA coding region (bp) & $4,287,642$ & $90.00 \%$ \\
DNA G+C content (bp) & $3,331,901$ & $70.08 \%$ \\
Number of replicons & 1 & \\
Extrachromosomal elements & 0 & \\
Total genes & 4,530 & $100.00 \%$ \\
RNA genes & 58 & $1.28 \%$ \\
rRNA operons & 3 & \\
tRNA genes & 47 & $1.04 \%$ \\
Protein-coding genes & 4,472 & $98.72 \%$ \\
Pseudo genes & 96 & $2.12 \%$ \\
Genes with function prediction (proteins) & 3,342 & $73.77 \%$ \\
Genes in paralog clusters & 2,354 & $51.96 \%$ \\
Genes assigned to COGs & 3,312 & $73.11 \%$ \\
Genes assigned Pfam domains & 3,450 & $76.16 \%$ \\
Genes with signal peptides & 1,332 & $29.40 \%$ \\
Genes with transmembrane helices & 1,070 & $23.62 \%$ \\
CRISPR repeats & 0 & \\
\hline
\end{tabular}


0

100000

200000

300000

400000

500000

600000

700000

300000

90000

1000000

1100000

1200000

1300000

1400000

1500000

1600000

1700000

1300000

1900000

2000000

2100000

2000000

2300000

2400000

2500000

2000000

2700000

2300000

2900000

3000000

3100000

3200000

3300000

3400000

3500000

3600000

3700000

300000

3900000

4000000

4100000

4200000

4300000

4400000

4500000

4600000

4700000
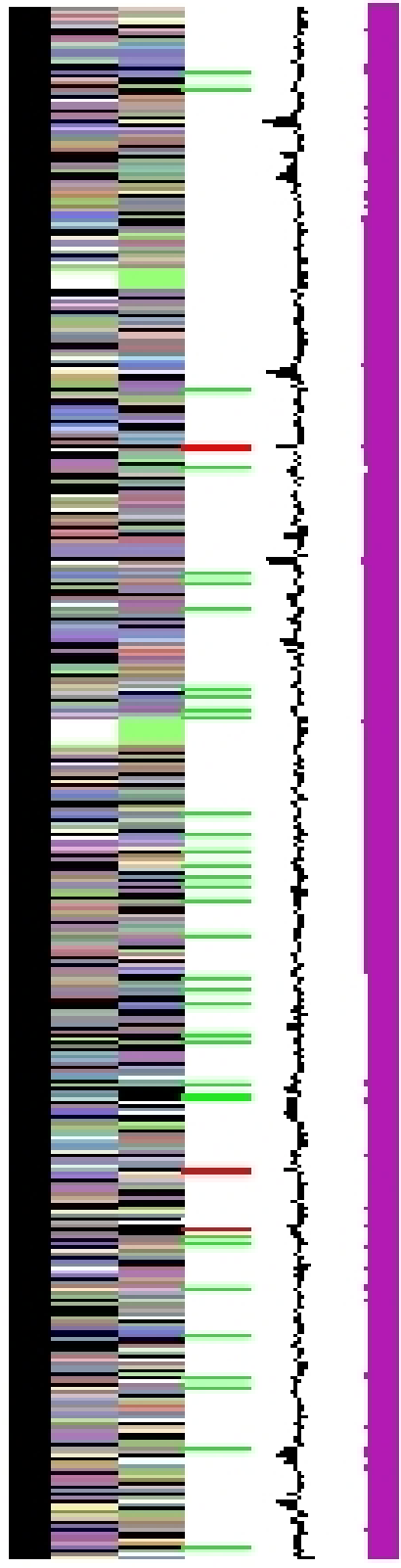

Figure 3. Graphical map of the chromosome. From left to the right: Genes on forward strand (color by COG categories), Genes on reverse strand (color by COG categories), RNA genes (tRNAs green, rRNAs red, other RNAs black), GC content, GC skew. 
Table 4. Number of genes associated with the general COG functional categories

\begin{tabular}{crrl}
\hline Code & value & \%age & Description \\
\hline J & 171 & 4.6 & Translation, ribosomal structure and biogenesis \\
A & 1 & 0.0 & RNA processing and modification \\
K & 394 & 10.6 & Transcription \\
L & 175 & 4.7 & Replication, recombination and repair \\
B & 2 & 0.1 & Chromatin structure and dynamics \\
D & 35 & 0.9 & Cell cycle control, cell division, chromosome partitioning \\
Y & 0 & 0.0 & Nuclear structure \\
V & 58 & 1.6 & Defense mechanisms \\
T & 190 & 5.1 & Signal transduction mechanisms \\
M & 156 & 4.2 & Cell wall/membrane biogenesis \\
N & 6 & 0.2 & Cell motility \\
Z & 0 & 0.0 & Cytoskeleton \\
W & 0 & 0.0 & Extracellular structures \\
U & 36 & 1.0 & Intracellular trafficking and secretion, and vesicular transport \\
O & 134 & 3.6 & Posttranslational modification, protein turnover, chaperones \\
C & 245 & 6.6 & Energy production and conversion \\
G & 259 & 7.0 & Carbohydrate transport and metabolism \\
E & 313 & 8.4 & Amino acid transport and metabolism \\
F & 91 & 2.4 & Nucleotide transport and metabolism \\
H & 194 & 5.2 & Coenzyme transport and metabolism \\
I & 179 & 4.8 & Lipid transport and metabolism \\
P & 176 & 4.7 & Inorganic ion transport and metabolism \\
Q & 152 & 4.1 & Secondary metabolites biosynthesis, transport and catabolism \\
R & 478 & 12.8 & General function prediction only \\
S & 282 & 7.6 & Function unknown \\
- & 1,218 & 26.9 & Not in COGs \\
\hline
\end{tabular}

\section{Acknowledgements}

The work conducted by the US Department of Energy Joint Genome Institute was supported by the Office of Sci-

\section{References}

1. Runmao H. Saccharomonospora azurea sp. nov., a new species from soil. Int I Syst Bacteriol 1987; 37:60-61. http://dx.doi.org/10.1099/00207713-37-1$\underline{60}$

2. Garrity G. NamesforLife. BrowserTool takes expertise out of the database and puts it right in the browser. Microbiol Today 2010; 37:9.

3. Euzéby JP. List of Bacterial Names with Standing in Nomenclature: a folder available on the internet. Int J Syst Bacteriol 1997; 47:590. PubMed http://dx.doi.org/10.1099/00207713-47-2-590

4. Yoon JH, Kim SB, Lee ST, Park YH. DNA-DNA relatedness between Saccharomonospora species: 'Saccharomonospora caesia' as a synonym of Saccharomonospora azurea. Int J Syst Bacteriol 1999; 49:671-673. http://dx.doi.org/10.1099/00207713-49-2-671

5. Kurup VP. Taxonomic study of some members of Micropolyspora and Saccharomonospora. Microbiologica 1981; 4:249-259. ence of the U.S. Department of Energy under Contract No. DE-AC02-05CH11231.

6. Kalakoutskii LV. A new species of the genus Micropolyspora - Micropolyspora caesia n. sp. [English translation of Microbiologiya]. Microbiology 1964; 33:765-768.

7. Skerman VBD, McGowan V, Sneath PHA. Approved Lists of Bacterial Names. Int J Syst Bacteriol 1980; 30:225-420. http://dx.doi.org/10.1099/00207713-30-1-225

8. Pati A, Sikorski J, Nolan M, Lapidus A, Copeland A, Glavina Del Rio T, Lucas S, Chen F, Tice H, Pitluck $\mathrm{S}$, et al. Complete genome sequence of Saccharomonospora viridis type strain (P101 ${ }^{\mathrm{T}}$ ). Stand Genomic Sci 2009; 1:141-149. PubMed http://dx.doi.org/10.4056/sigs.20263

9. Wu D, Hugenholtz P, Mavromatis K, Pukall R, Dalin E, Ivanova NN, Kunin V, Goodwin L, Wu M, Tindall BJ, et al. A phylogeny-driven Genomic Encyclopaedia of Bacteria and Archaea. Nature 2009; 462:1056-1060. PubMed http://dx.doi.org/10.1038/nature08656 
10. Carbon Active Enzyme Database. http://www.cazy.org

11. Liu Z, Li Y, Zheng L, Huang YJ, Li WJ. Saccharomonospora marina sp. nov., isolated from an ocean sediment of the East China Sea. Int J Syst Evol Microbiol 2010; 60:1854-1857. PubMed http://dx.doi.org/10.1099/ijs.0.017038-0

12. Al-Zarban SS, Al-Musaallam AA, Abbas I, Stackebrandt E, Kroppenstedt RM.

Saccharomonospora halophila sp. nov., a novel halophilic actinomycete isolated from marsh soil in Kuwait. Int J Syst Evol Microbiol 2002; 52:555-558. PubMed

13. Syed DG, Tang SK, Cai M, Zhi XY, Agasar D, Lee JC, Kim CJ, Jiang CL, Xu CL, Li WJ.

Saccharomonospora saliphila sp. nov., a halophilic actinomycete from an Indian soil. Int J Syst Evol Microbiol 2008; 58:570-573. PubMed

http://dx.doi.org/10.1099/ijs.0.65449-0

14. Li WJ, Tang SK, Stackebrandt E, Kroppenstedt RM, Schumann P, Xu LH, Jiang CL. Saccharomonospora paurometabolica sp. nov., a moderately halophilic actinomycete isolated from soil in China. Int J Syst Evol Microbiol 2003; 53:1591-1594. PubMed http://dx.doi.org/10.1099/ijs.0.02633-0

15. Jin X, Xu LH, Mao PH, Hseu TH, Jiang CL. Description of Saccharomonospora xinjiangensis sp. nov. based on chemical and molecular classification. Int J Syst Bacteriol 1998; 48:1095-1099. PubMed http://dx.doi.org/10.1099/00207713-48-4-1095

16. Altschul SF, Gish W, Miller W, Myers EW, Lipman DJ. Basic local alignment search tool. J Mol Biol 1990; 215:403-410. $\underline{\text { PubMed }}$

17. Korf I, Yandell M, Bedell J. BLAST, O'Reilly, Sebastopol, 2003.

18. DeSantis TZ, Hugenholtz P, Larsen N, Rojas M, Brodie EL, Keller K, Huber T, Dalevi D, Hu P, Andersen GL. Greengenes, a chimera-checked 16S rRNA gene database and workbench compatible with ARB. Appl Environ Microbiol 2006; 72:50695072. PubMed http://dx.doi.org/10.1128/AEM.03006-05

19. Porter MF. An algorithm for suffix stripping. Program: electronic library and information systems 1980; 14:130-137.

20. Lee C, Grasso C, Sharlow MF. Multiple sequence alignment using partial order graphs. Bioinformatics 2002; 18:452-464. PubMed http://dx.doi.org/10.1093/bioinformatics/18.3.452

21. Castresana J. Selection of conserved blocks from multiple alignments for their use in phylogenetic analysis. Mol Biol Evol 2000; 17:540-552. PubMed http://dx.doi.org/10.1093/oxfordjournals.molbev.a0 $\underline{26334}$
22. Stamatakis A, Hoover $\mathrm{P}$, Rougemont J. A rapid bootstrap algorithm for the RAxML web servers. Syst Biol 2008; 57:758-771. PubMed http://dx.doi.org/10.1080/10635150802429642

23. Hess PN, De Moraes Russo CA. An empirical test of the midpoint rooting method. Biol J Linn Soc Lond 2007; 92:669-674. http://dx.doi.org/10.1111/j.1095$\underline{8312.2007 .00864 . x}$

24. Pattengale ND, Alipour M, Bininda-Emonds ORP, Moret BME, Stamatakis A. How many bootstrap replicates are necessary? Lect Notes Comput Sci 2009; 5541:184-200. http://dx.doi.org/10.1007/978-3642-02008-7_13

25. Swofford DL. PAUP*: Phylogenetic Analysis Using Parsimony (*and Other Methods), Version 4.0 b10. Sinauer Associates, Sunderland, 2002.

26. Liolios K, Chen IM, Mavromatis K, Tavernarakis N, Kyrpides NC. The genomes on line database (GOLD) in 2009: Status of genomic and metagenomic projects and their associated metadata. Nucleic Acids Res 2010; 38:D346-D354. PubMed http://dx.doi.org/10.1093/nar/gkp848

27. Land M, Lapidus A, Mayilraj S, Chen R, Copeland A, Glavina Del Rio T, Nolan M, Lucas S, Tice H, Cheng JF, et al. Complete genome sequence of Actinosynnema mirum type strain $\left(101^{\mathrm{T}}\right)$. Stand Genomic Sci 2009; 1:46-53. PubMed http://dx.doi.org/10.4056/sigs.21137

28. Liolios K, Sikorski J, Jando M, Lapidus A, Copeland A, Glavina Del Rio T, Nolan M, Lucas S, Tice H, Cheng JF, et al. Complete genome sequence of Thermobispora bispora type strain (R51 ' ). Stand Genomic Sci 2010; 2:318-326. PubMed http://dx.doi.org/10.4056/sigs.962171

29. Tang SK, Wang Y, Klenk HP, Shi R, Lou K, Zhang YJ, Chen C, Ruan JS, Li WJ. Actinopolyspora alba sp. nov. and Actinopolyspora erythraea sp. nov., isolated from a salt field, and reclassification of Actinopolyspora iraqiensis Ruan et al. 1994 as a heterotypic synonym of Saccharomonospora halophila. Int I Syst Evol Microbiol 2011; 61:16931698. PubMed http://dx.doi.org/10.1099/ijs.0.022319-0

30. Field D, Garrity G, Gray T, Morrison N, Selengut J, Sterk P, Tatusova T, Thomson N, Allen MJ, Angiuoli $\mathrm{SV}$, et al. The minimum information about a genome sequence (MIGS) specification. Nat Biotechnol 2008; 26:541-547. PubMed http://dx.doi.org/10.1038/nbt1360

31. Woese CR, Kandler O, Wheelis ML. Towards a natural system of organisms. Proposal for the domains Archaea and Bacteria. Proc Natl Acad Sci USA 
Klenk et al.

1990; 87:4576-4579. PubMed

http://dx.doi.org/10.1073/pnas.87.12.4576

32. Garrity GM, Holt JG. The Road Map to the Manual. In: Garrity GM, Boone DR, Castenholz RW (eds), Bergey's Manual of Systematic Bacteriology, Second Edition, Volume 1, Springer, New York, 2001, p. 119-169.

33. Stackebrandt E, Rainey FA, Ward-Rainey NL. Proposal for a new hierarchic classification system, Actinobacteria classis nov. Int / Syst Bacteriol 1997; 47:479-491. http://dx.doi.org/10.1099/00207713$\underline{47-2-479}$

34. Zhi XY, Li WJ, Stackebrandt E. An update of the structure and $16 \mathrm{~S}$ rRNA gene sequence-based definition of higher ranks of the class Actinobacteria, with the proposal of two new suborders and four new families and emended descriptions of the existing higher taxa. Int / Syst Evol Microbiol 2009; 59:589-608. PubMed http://dx.doi.org/10.1099/ijs.0.65780-0

35. Buchanan RE. Studies in the nomenclature and classification of bacteria. II. The primary subdivisions of the Schizomycetes. J Bacteriol 1917; 2:155-164. PubMed

36. Labeda DP, Goodfellow M, Chun J, Zhi X-Y, Li W-J. Reassessment of the systematics of the suborder Pseudonocardineae: transfer of the genera within the family Actinosynnemataceae Labeda and Kroppenstedt 2000 emend. Zhi et al. 2009 into an emended family Pseudonocardiaceae Embley et al. 1989 emend. Zhi et al. 2009. Int / Syst Evol Microbiol 2011; 61:1259-1264. PubMed http://dx.doi.org/10.1099/ijs.0.024984-0

37. List Editor. Validation List no. 29. Validation of the publication of new names and new combinations previously effectively published outside the IJSB. Int J Syst Bacteriol 1989; 39:205-206. http://dx.doi.org/10.1099/00207713-39-2-205

38. Embley MT, Smida J, Stackebrandt E. The phylogeny of mycolate-less wall chemotype IV Actinomycetes and description of Pseudonocardiaceae fam. nov. Syst Appl Microbiol 1988; 11:44-52. http://dx.doi.org/10.1016/S0723-2020(88)80047-X

39. Nonomura H, Ohara Y. Distribution of actinomycetes in soil. X. New genus and species of monosporic actinomycetes in soil. J Ferment Technol 1971; 49:895-903.

40. BAuA. 2010, Classification of Bacteria and Archaea in risk groups. http://www.baua.de TRBA 466, p. 194.
41. Ashburner M, Ball CA, Blake JA, Botstein D, Butler $\mathrm{H}$, Cherry JM, Davis AP, Dolinski K, Dwight SS, Eppig JT, et al. Gene ontology: tool for the unification of biology. The Gene Ontology Consortium. Nat Genet 2000; 25:25-29. PubMed http://dx.doi.org/10.1038/75556

42. Wink JM. Compendium of Actinobacteria. http://www.dsmz.de/microorganisms/wink_pdf/DS M44631.pdf.

43. List of growth media used at DSMZ: http://www.dsmz.de/catalogues/cataloguemicroorganisms/culture-technology/list-of-mediafor-microorganisms.html.

44. Gemeinholzer B, Dröge $G$, Zetzsche $H$, Haszprunar G, Klenk HP, Güntsch A, Berendsohn WG, Wägele JW. The DNA Bank Network: the start from a German initiative. Biopreserv Biobank 2011; 9:51-55. http://dx.doi.org/10.1089/bio.2010.0029

45. The DOE Joint Genome Institute. http://www.jgi.doe.gov

46. Phrap and Phred for Windows. MacOS, Linux, and Unix. http://www.phrap.com

47. Zerbino DR, Birney E. Velvet: algorithms for de novo short read assembly using de Bruijn graphs. Genome Res 2008; 18:821-829. PubMed http://dx.doi.org/10.1101/gr.074492.107

48. Han C, Chain P. Finishing repeat regions automatically with Dupfinisher. In: Proceeding of the 2006 international conference on bioinformatics \& computational biology. Arabnia HR, Valafar H (eds), CSREA Press. June 26-29, 2006: 141-146.

49. Lapidus A, LaButti K, Foster B, Lowry S, Trong S, Goltsman E. POLISHER: An effective tool for using ultra short reads in microbial genome assembly and finishing. AGBT, Marco Island, FL, 2008.

50. Hyatt $\mathrm{D}$, Chen GL, Locascio PF, Land ML, Larimer FW, Hauser LJ. Prodigal Prokaryotic Dynamic Programming Genefinding Algorithm. BMC Bioinformatics 2010; 11:119. PubMed http://dx.doi.org/10.1186/1471-2105-11-119

51. Pati A, Ivanova N, Mikhailova N, Ovchinikova G, Hooper SD, Lykidis A, Kyrpides NC. GenePRIMP: A Gene Prediction Improvement Pipeline for microbial genomes. Nat Methods 2010; 7:455-457. PubMed http://dx.doi.org/10.1038/nmeth.1457

52. Markowitz VM, Ivanova NN, Chen IMA, Chu K, Kyrpides NC. IMG ER: a system for microbial genome annotation expert review and curation. Bioinformatics 2009; 25:2271-2278. PubMed http://dx.doi.org/10.1093/bioinformatics/btp393 